\title{
Effect of nickel loading on the performance of nano- and micro-sized ZSM-5 catalysts for methanol to hydrocarbon conversion
}

Zhaoxi Zhang ${ }^{1}$ Bonan Liu ${ }^{1}$, Fei Liu ${ }^{1,2 *}$, Yongxiang Zhao ${ }^{3}$ Tiancun Xiao ${ }^{1,3 * *}$

1. Inorganic Chemistry Laboratory, University of Oxford, South Parks Road, Oxford, OX1 3QR, UK. * Corresponding author: xiao.tiancun@chem.ox.ac.uk

2. College of Chemistry and Chemical Engineering. Guizhou University, Guiyang City, Guizhou, P R China, * ce.feiliu@gzu.edu.cn

3. School of Chemistry and Chemical Engineering, Shanxi University, Taiyuan 030006, Shanxi Province, PR China

\begin{abstract}
Methanol to hydrocarbon process is becoming increasingly important as methanol can be manufactured from flare gas, biomass, shale gas and coal. In this work, micro- and nano- sized ZSM-5 zeolites have been modified with low level nickel loading and tested for methanol to hydrocarbon process. It is shown that nano-sized ZSM-5 catalyst doped with nickel with or without $\mathrm{H}_{2}$ reduction has higher yield of hydrocarbon than the micro-sized ZSM-5 catalyst. Pretreatment of the NiO/ZSM-5 catalyst with $\mathrm{H}_{2}$ reduction does not decrease aromatics yield in the hydrocarbon products, but in contrast increases the yield of $\mathrm{C}_{1}-\mathrm{C}_{4}$ gaseous products, which may be due to the lower loading (1.0\% in wt.) of nickel metal substitution. The introduction of NiO to ZSM-5 catalyst increases acid amount and also acid strength, which may be due to the nickel entering the framework, thus changing the coordination environment of Si and Al. The structure of nano-sized ZSM-5 catalyst is more affected by the loading of nickel, such as more $\mathrm{AlO}_{5}$ units. In terms of catalytic performance, nano-sized ZSM-5 catalyst has high yield for hydrocarbon production, less gaseous yield, and less aromatics, which is probably due to the shorter distance for the diffusion and contact time of the dehydrated products over the acid sites.
\end{abstract}

Key words: methanol to hydrocarbon, nickel doping, nano-sized, ZSM-5 


\section{Introduction}

Methanol has been a platform for reduction of fossil fuels consumption, recycling excess atmospheric $\mathrm{CO}_{2}$, providing renewable fuels and feedstock for the chemical industry, because methanol can be produced from biomass, $\mathrm{CO}_{2}$ hydrogenation natural gas or any gasifiable carbonaceous material, such as petroleum and coal.[1-3] The conversion of methanol to hydrocarbons (MTH) is a key technology in the methanol platform, which is generally denoted as the MTH reaction, where methanol is converted to gasoline over ZSM-5 derived catalysts, firstly discovered by Mobile [4, 5]

MTH process and products disdepends on acid strength, acid site density, catalyst topology, temperature, pressure, space velocity and other process conditions [[6-8]. Due to the formation of bigger molecules from methanol, which is relatively small, faster mass transfer is highly needed to decrease the diffusion. It has been reported that diffusion rate has a second-order inverse dependence on the size of catalyst crystal $[7,9,10]$, smaller sizes of catalyst crystallites would be of help to promote the mass transfer. So far, there have been lots of studies on the synthesizing nano-sized zeolite for methanol to hydrocarbon process, and it is shown that the smaller crystallite does increase the yield of light olefins, adding high loading of transition metal can help the hydrogenation reaction and thus decreasing the aromatics content in the liquid yield. [10-14] However, few researches have been carried out in the effect of low loading nickel on the micro-sized and nano-sized ZSM-5 catalyst and their performance for methanol to hydrocarbon.

Modification of ZSM-5 catalyst with metal oxide has been widely studied, but these metal loading modifications focus on the micro-sized ZSM-5 catalysts, [15-19] and the metal loadings are often very high, which has much more complex distribution in the catalyst $[6,19]$. Very few studies have been carried out on the effect of low metal loading on nano-sized ZSM-5 catalyst.

The aim of this work is to study the effect of the low nickel loading on the structure and acidity of the micro- and nano-sized ZSM-5, and their properties and 
performance for methanol to hydrocarbon have been tested. It is found that loading $1 \mathrm{wt} \%$ of NiO onto ZSM-5 catalyst significant changes the acidity of the catalyst, a high temperature hydrogen treatment of the supported nickel oxide catalyst leads to high acidity and also more aromatics. However, overall, the nano-ZSM-5 supported $\mathrm{Ni}$ catalyst gives more gasoline yield and less aromatics, which can be explained by the shorter diffusion distance, thus avoiding deep dehydration process.

\section{Experimental}

\section{Preparation of Catalyst}

In this research, the micro-sized and nano-sized ZSM-5 catalysts were supplied by catalyst plant of Nankai University. The $1.0 \mathrm{wt} \%$ of $\mathrm{NiO}$ containing ZSM-5 catalyst samples were prepared using impregnation method. In the nickel loading, $1.5 \mathrm{ml}$ nickel nitrate solution $\left(0.188 \mathrm{M} \mathrm{Ni}\left(\mathrm{NO}_{3}\right)_{2} .6 \mathrm{H}_{2} \mathrm{O}\right.$ from Sigma Aldrich, A.R.) is impregnated with $2.0 \mathrm{~g}$ of the nano or micro-sized ZSM-5 powder (60-100 mesh), placed at ambient condition for 4 hours while stirring. They were then dried at $120{ }^{\circ} \mathrm{C}$ for 2 hours and calcined at $400{ }^{\circ} \mathrm{C}$ for 4 hours, and then cooled down to get the supported oxide. Then half of the samples were taken out and loaded into a quartz reactor and reduced in flowing $\mathrm{H}_{2}\left(\mathrm{GHSV}\right.$ of $\mathrm{H}_{2}$ at $6000 \mathrm{~h}^{-1}$ ) from room temperature to $500{ }^{\circ} \mathrm{C}$ and held at $500{ }^{\circ} \mathrm{C}$ for 4 hours, then cooled down to room temperature in flowing $\mathrm{H}_{2}$. The treatment with pure $\mathrm{H}_{2}$ at high temperature is to reduce the $1.0 \mathrm{wt} \%$ of $\mathrm{NiO}$ into metal Ni. The $\mathrm{H}_{2}$-reduced sample is marked as Ni/nano-sized ZSM-5 and Ni/micro-sized ZSM-5.

\section{Catalyst testing}

Catalyst performance tests were carried out in a fixed bed micro-reactor system (Beijing KLYT Co. Ltd, China). Methanol was injected using a HPLC pump and vaporized at $150{ }^{\circ} \mathrm{C}$ before entering the reactor. Flowing nitrogen $(20 \mathrm{ml} / \mathrm{min})$ was used as carrier gas and internal standard for gas product quantification. The reaction took place in a tubular stainless steel reactor at $400{ }^{\circ} \mathrm{C}$ under the pressure of $1 \mathrm{~atm}$; typically $1.0 \mathrm{~g}$ of catalyst loaded in the reactor with a setting methanol Weight Hourly Space Velocity (WHSV) of $2 \mathrm{~h}^{-1}$. The gas products were analyzed using a GC system 
(Shimadzu GC-2010SE) equipped with a thermal conductivity detector (TCD) for non-hydrocarbons and flame ionized detector (FID) for hydrocarbons every 30 minutes, after methanol injection started. The gas product separation in GC system employed a RESTEK MXT-1HT column.

The calculation of the conversion and product selectivity are carried out according to the following equations:

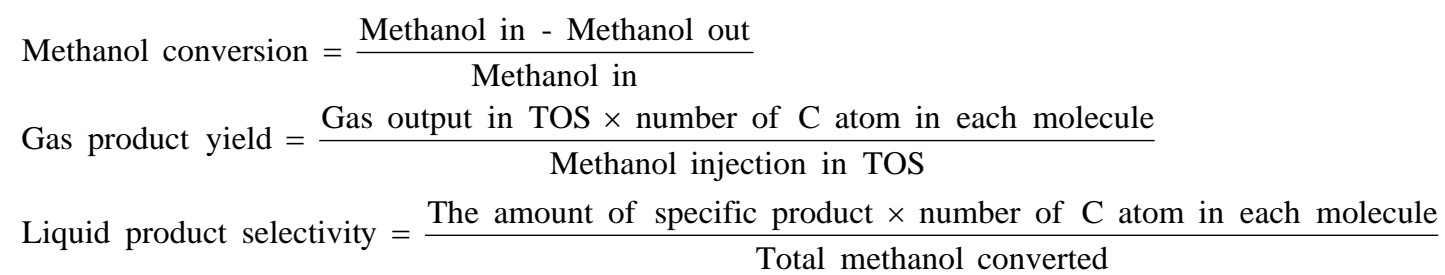

The liquid products were collected after the reaction, separated into water phase (water was generated in the reaction) and oil phase (hydrocarbon products) via still standing, both of which were then analyzed with an offline GC-MS system using FID detector (Shimadzu GCMS-QP2010 Ultra High-end). Separation of different liquid components proceeded in a SHIM-5MS column..

The methanol conversion was defined by amount of methanol consumed compared to the total methanol fed. The amount of methanol remaining in the liquid product (both oil phase and water phase) is analyzed with offline GC-MS. The gas product time-on-stream (TOS) yield (mol \%) was calculated by comparing the instantaneous gas product methanol consumption (mol/min) with methanol injection rate $(\mathrm{mol} / \mathrm{min})$. The corresponding benzene, toluene, and xylenes (BTX) selectivity (taken after 5 hours) was calculated from the methanol consumption of selected products (mol.) and total methanol converted (mol.).

\section{Characterization methods}

The crystalline phase changes of the supported metal and zeolites were analysed with a PANalytical X'Pert PRO Diffractometer using $\mathrm{Cu} \mathrm{K} \alpha 1$ radiation, the scan diffraction angle operated from $5^{\circ}$ to $90^{\circ}$ (2 $\theta$ angular range) and a scan rate of $0.8^{\circ} / \mathrm{min}$ in $2 \theta$ X-Ray Powder diffraction (XRD), 
The acidity of the catalyst is measured using a $\mathrm{NH}_{3}$-TPD method (TP-5078 Auto TPD system, Xianquan Co. Ltd, China). The catalyst samples were loaded into the reactor pre-treated in $\mathrm{N}_{2}$ at $300{ }^{\circ} \mathrm{C}$ for $2 \mathrm{~h}$ to remove the adsorbed moisture. $\mathrm{NH}_{3}$ was introduced at $\mathrm{NH}_{3}: \mathrm{N}_{2}=1: 3$ on to the pre-treated catalysts at $120^{\circ} \mathrm{C}$ for $30 \mathrm{~min}$, and the system was then cooled down to room temperature for $1 \mathrm{~h}$ in pure $\mathrm{N}_{2}$. The samples were then heated at $8{ }^{\circ} \mathrm{C} / \mathrm{min}$ from room temperature to $600{ }^{\circ} \mathrm{C}$, the desorbed $\mathrm{NH}_{3}$ was recorded with a Thermal Conductivity Detector (TCD).

The BET analysis proceeded with a Micromeritics Gemini VI BET surface area analyzer. The total surface area was calculated from adsorption data at $\mathrm{p} / \mathrm{p}_{0}=0.05$ and the total volume of all the tested samples was measured at $\mathrm{p} / \mathrm{p}_{0}=0.995$.

The SEM images were obtained with a JEOL scanning microscope 840F (JSM840F). The sample powder was deposited onto a dust-free scanning platform and trapped on the surface before analysis. The resolution was carefully adjusted to make sure the sharp and clear edge of the zeolite crystalline grains could be observed with as many as optical details of the external surface. TEM measurements were undertaken using a JEM-2100UHR microscope (200kV).

${ }^{27} \mathrm{Al},{ }^{29} \mathrm{Si},{ }^{13} \mathrm{C}$ and ${ }^{1} \mathrm{H}$ NMR experiments carried out with a Varian VNMRS spectrometer at ambient temperature with a resonance frequency of 104.198, 79.438 and 100.562 MHz, respectively. Cross Polarization (CP) for ${ }^{13} \mathrm{C}$ NMR and Direct Excitation (DE) for ${ }^{27} \mathrm{Al}$ and ${ }^{29} \mathrm{Si}$ were employed in the experiment. The ${ }^{27} \mathrm{Al} \mathrm{NMR}$ measurements were performed on a $4 \mathrm{~mm}$ probe, with an acquisition time of $20.0 \mathrm{~ms}$, a recycle time of 5.0 second, and a sample spinning rate of $12.118 \mathrm{KHz}$. The ${ }^{29} \mathrm{Si}$ 
NMR spectra were recorded with a $6 \mathrm{~mm}$ probe at sample spinning rate of $6 \mathrm{KHz}$, in an acquisition time of $20.0 \mathrm{~ms}$, with recycle delay of 5.0 second. The ${ }^{13} \mathrm{C}$ CP NMR used a $6 \mathrm{~mm}$ probe, with data acquisition in $30.0 \mathrm{~ms}$, recycle delay of 2.0 second and sample spinning rate at $6 \mathrm{KHz}$.

\section{Results and discussion}

\subsection{Structural properties of the ZSM-5 samples}

The XRD measurement results of the synthesized micro- and nano-sized ZSM-5 zeolites with the same $\mathrm{Si} / \mathrm{Al}$ ratio (38.1) are shown in Fig. 1. The two samples exhibited typical ZSM-5 zeolite structure without the appearance of any peaks rather than the ZSM-5, although the diffraction intensity of nano-sized ZSM-5 is much weaker. This suggests that the crystalline phases of the synthesized samples have quite high purity of the ZSM-5 zeolite, the lower diffraction peaks of the nano-sized ZSM-5 zeolite sample suggests that the crystallite size of the sample is small, which has shorter ordered length. The strong diffraction peaks in the micron-HZSM-5 suggest it has the highest crystallinity, assuming it is has the relative $100 \%$ crystallinity. The relative crystallinity of nano-sized ZSM-5 is $40 \%$ compared to the diffraction peak intensity of the micro-sized ZSM-5. 

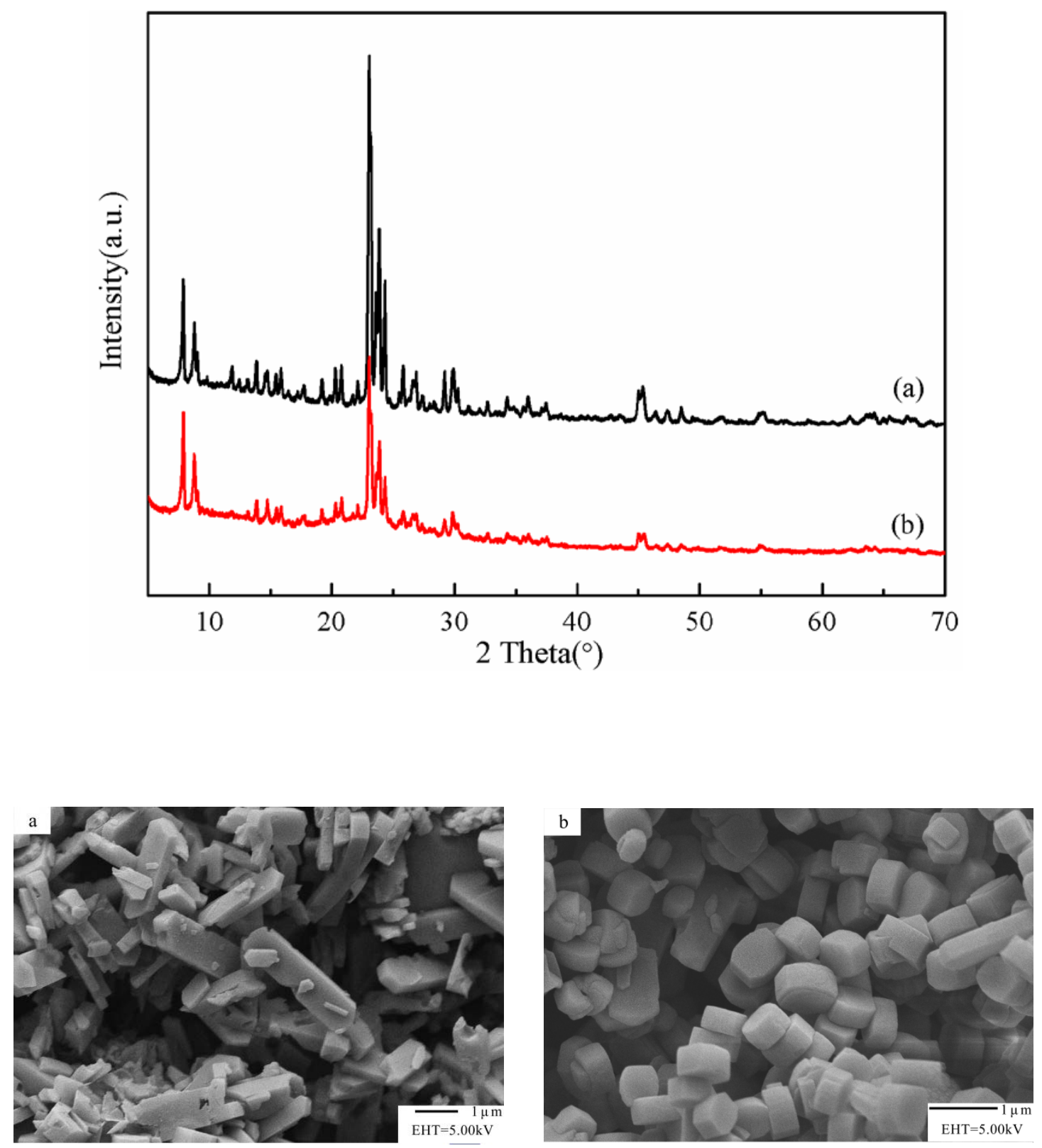

Fig.1 XRD patterns and SEM images of ZSM-5, (a) micro-sized ZSM-5, (b)

nano-sized ZSM-5

The scanning electron microscopes (SEM) images of the synthesized micro-sized and nano-sized ZSM-5 catalysts are shown in Fig 1 too. As expected, the crystallite size of the micro ZSM-5 sample is about 2um long and $0.4 \mu$ m wide, composing of rod like particles. The morphologies of the nano-ZSM-5 are pellet like, with diameter of $0.3 \mu \mathrm{m}$, and $0.2 \mu \mathrm{m}$ thickness. There are also a few rod-like crystallites, however with very low content. The SEM results are in agreement with the XRD 
measurement, and show that the synthesis method is useful to control the sizes of the ZSM-5 catalyst morphologies.

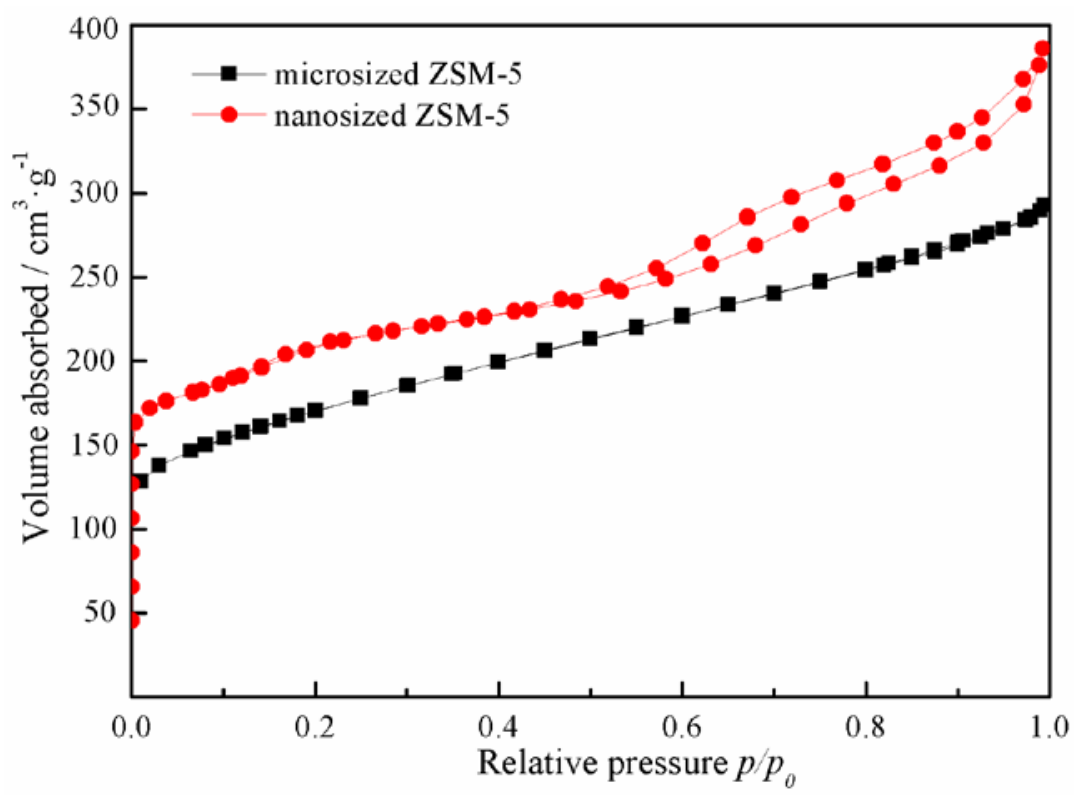

Fig.2 $\mathrm{N}_{2}$ adsorption-desorption isotherms of micro-sized and nano-sized ZSM-5

The BET $\mathrm{N}_{2}$ adsorption curves of the nano- and micro-sized ZSM-5 zeolites are shown in Fig 2. It is seen that the micro-sized ZSM-5 zeolite shows a typical type II curves, where the adsorption-desorption are in good overlap, which suggest that the ZSM-5 powders with diameters exceeding micro-pores in it. This is indeed in agreement with the SEM and XRD results. For the nano-sized ZSM-5 catalyst, it shows a typical V adsorption-desorption curves, suggesting it has porous adsorbtion with pores in the range of 1.5-100 nm.

\section{${ }^{1} \mathrm{H}$ MAS NMR analysis}



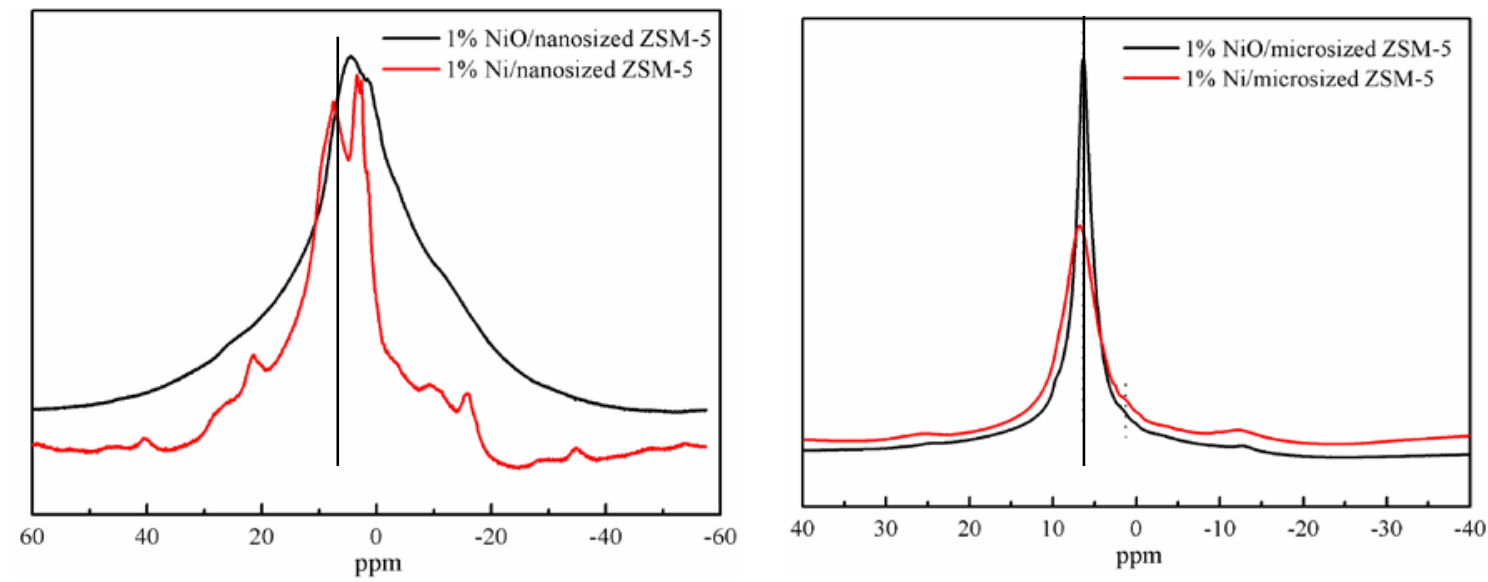

Fig. $3{ }^{1} \mathrm{H}$ MAS NMR spectra of $1 \% \mathrm{NiO}$ and Ni supported over (a) nano-sized ZSM-5 and (b) micro-sized ZSM-5

The ${ }^{1} \mathrm{H}$ NMR spectra of the nickel containing nano and micro-sized zeolites are shown in Figs 3-a and b. For the nano-sized ZSM-5 supported NiO, a broad NMR spectrum is see with the main band at $4.5 \mathrm{ppm}$, which is a typical for bridging $\mathrm{OH}$ groups $(\mathrm{Si}(\mathrm{OH}) \mathrm{Al})$ in the a-cages of ZSM-5, with a second peak at about zeolite A weak signals at $0.5 \mathrm{ppm}$ mainly caused by silanol groups located at framework defects [20,21] After flowing $\mathrm{H}_{2}$ treatment, the ${ }^{1} \mathrm{H}$ NMR peaks changes significantly, and the peak is becoming narrow with clear two peaks at $1.3 \mathrm{ppm}$, which is ascribed to the surface $\mathrm{Al}-\mathrm{OH}$ or $\mathrm{Ni}-\mathrm{OH}$ group, or the terminal silanol group. A low field shifted peak is seen at $7.8 \mathrm{ppm}$, which is attentively assigned to the disturbed bridging $\mathrm{OH}$ group in ZSM-5. The narrowing width of the peak may be due to the heat treatment which can remove the absorbed moisture of water.

In the micro-sized ZSM-5 sample ${ }^{1} \mathrm{H}$ NMR spectra have obvious difference with the nano-sized ZSM-5. A main sharp peak is seen at 7.2 ppm, which is assigned to the disturbed bridging $\mathrm{OH}$ group in $\mathrm{Si}(\mathrm{OAl})_{2} \mathrm{OHAl}$ [20]. It shifted slightly to the low field with a broader peak, which does not have substantial changes. These results show that the micro-sized ZSM-5 is more stable than the nano-sized ZSM-5, and $\mathrm{H}_{2}$ treatment has more influence on the nano-ZSM-5 catalyst.

\section{${ }^{27} \mathrm{Al}$ MAS NMR analysis}



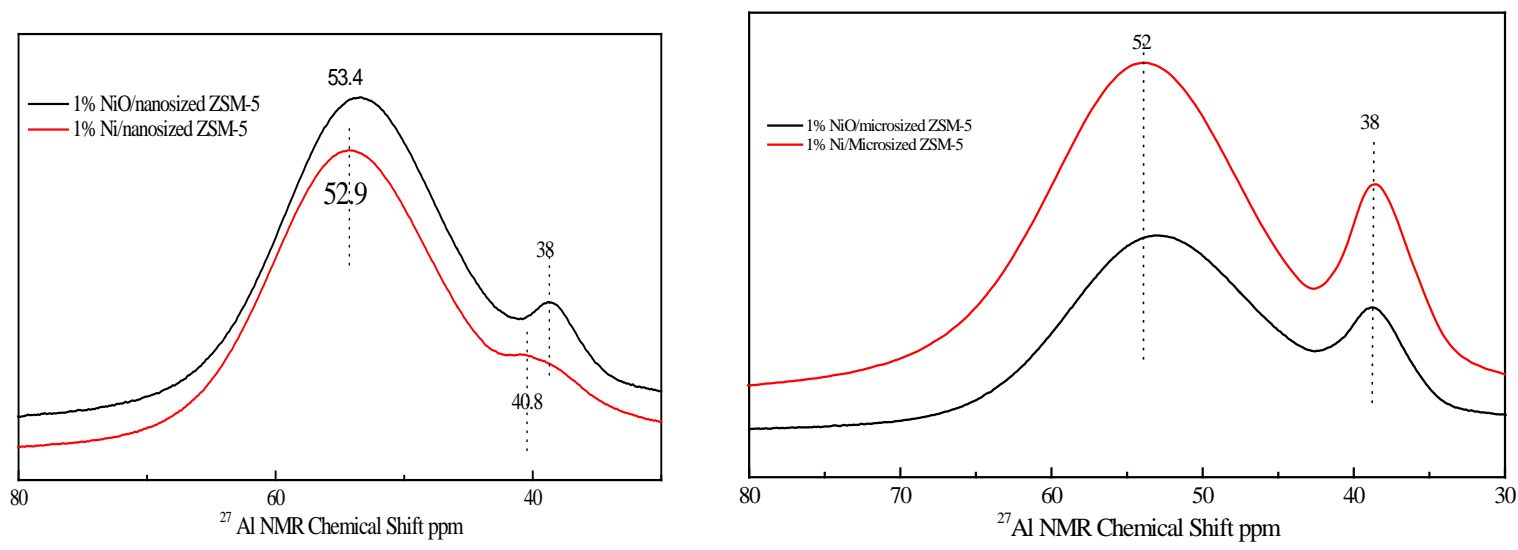

Fig.4 $\quad{ }^{27} \mathrm{Al}$ MAS NMR spectra of $1 \% \mathrm{NiO}$ and Ni supported (a) nano-sized ZSM-5 and (b) micro-sized ZSM-5

The ${ }^{27} \mathrm{Al}$ Mas NMR spectra of the ZSM-5 supported nickel catalysts with different nickel treatment are given in Fig.4. The nano-ZSM-5 zeolite without Ni loading without nickel shows one NMR peak centering at 53.5 ppm, which is assigned to tetrahedral coordinated $\mathrm{AlO}_{4}$ in the framework of the zeolite. When NiO is loaded over the nano-ZSM-5 zeolite, besides the main NMR peak at 53.4 ppm, which is the framework tetrahedrally coordinated $\mathrm{Al}$, a small should peak is seen at $38.0 \mathrm{ppm}$, which can be assigned to the non-framework tetrahedrally coordinated $\mathrm{Al}$ atom [21], or because of the nano-sized zeolite, or the unwell crystallized very small ZSM-5 zeolite. [22] When the nano-sized NiO/ZSM-5 is treated with flowing $\mathrm{H}_{2}$ to high temperature it is interesting to see that the peak at $38.0 \mathrm{ppm}$ tends to disappear while the peak at about $53.0 \mathrm{ppm}$ is almost unchanged This results show that the thermal treatment with $\mathrm{H}_{2}$ to high temperature may help the non-framework tetradedrally coordinated to enter the framework, which may leads to more stronger acidic sites.

For the micro-sized ZSM-5 zeolite, the loading of $1.0 \mathrm{wt} \% \mathrm{NiO}$, an even stronger non-framework tetrahedrally coordinated $\mathrm{AlO}_{4}$ peak is seen compared to the main framework $\mathrm{AlO}_{4}$ unit. However, similar to the nano-sized ZSM-5 zeolite, the high temperature flowing $\mathrm{H}_{2}$ treatment of the NiO/ZSM-5 also reduces the signal intensity of the non-framework $\mathrm{AlO}_{4}$. This suggests that the loading of low content NiO onto ZSM-5 zeolite both to nano and micro-sized lead to some framework tetrahedrally coordinated $\mathrm{AlO}_{4}$ unit dis-located outside of the framework, maybe due to the partially substitution of Al by Ni in the framework 


\section{${ }^{29}$ Si MAS NMR analysis}
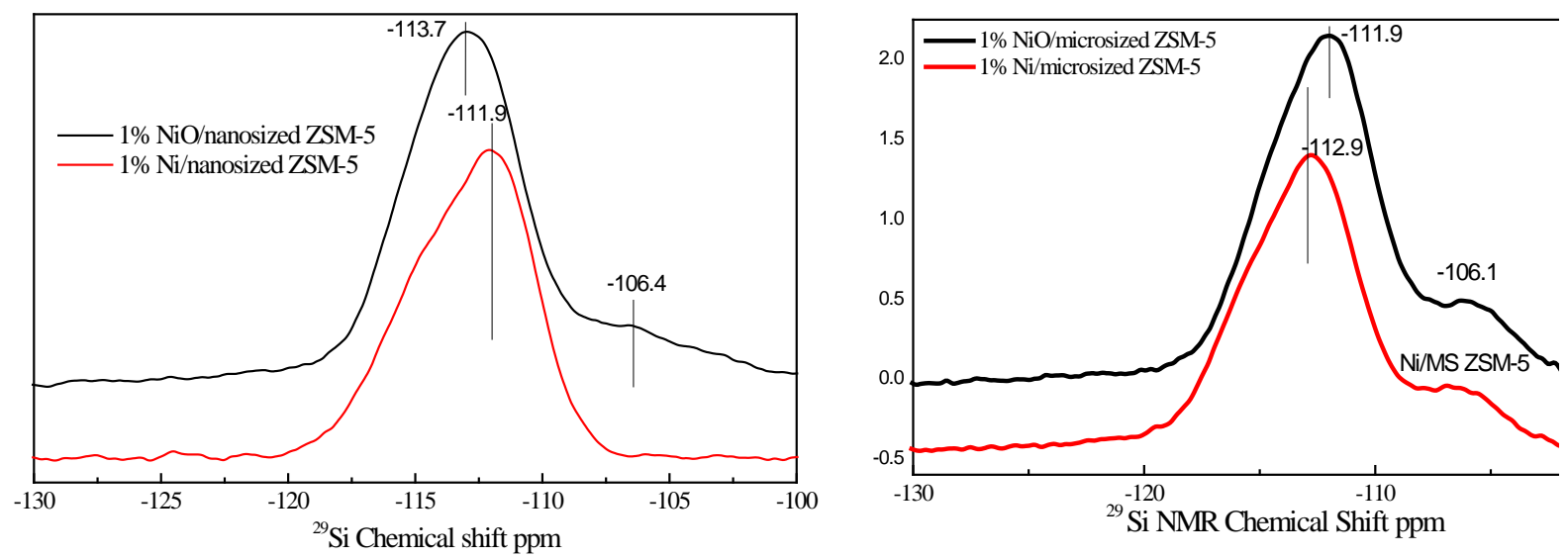

Fig. ${ }^{29} \mathrm{Si}$ MAS NMR spectra of $1 \% \mathrm{NiO}$ and Ni supported (a) nano-sized ZSM-5 and micro-sized ZSM-5

The ${ }^{29}$ Si MAS NMR spectra of the micro-sized and nano-sized ZSM-5 supported nickel samples catalysts shown in Fig 5. The NiO/Nano-ZSM-5 sample shows one main NMR peaks at $113.7 \mathrm{ppm}$, which is assigned to the tetrahedral $\mathrm{SiO}_{4}$ linked with $4 \mathrm{Si}$ atoms, e.g.., $\mathrm{Q} 4(0 \mathrm{Al})$, There is a very small peak at about $106.4 \mathrm{pp}$, which is due to the tetrahedral $\mathrm{SiO}_{4}$ in the framework lined with $3 \mathrm{Si}$ and $1 \mathrm{Al}$, e.g., Q3(1Al). This suggest that there exist very little $\mathrm{Al}$ in the framework of NiO/nano-ZSM-5. However, after flowing $\mathrm{H}_{2}$ treatment at $600{ }^{\circ} \mathrm{C}$, the small peak at 106.0 ppm almost disappeared, while the main Q4(0Al) NMR peak shifted slightly to higher field, centering at 111.9 ppm, which may have some effect of long range aluminum atoms from the framework. The treatment of the NiO/nano-ZSM-5 does cause the re-location of aluminum in the framework. In the micro-sized ZSM-5 supported NiO sample, the ${ }^{29} \mathrm{Si}$ MAS NMR spectra is shown in Fig 5-b. in the oxide sample the main peak is seen at 111.9 ppm, with a small peak at $106.1 \mathrm{ppm}$, which are assigned to Q4(0Al) and Q4(1Al).. The relatively stronger peak at $106.1 \mathrm{ppm}$ implying that more framework $\mathrm{Al}$ is present in the micro-sized ZSM-5 supported NiO sample. After thermal treatment in flowing $\mathrm{H}_{2}$, the main peak of ${ }^{29}$ Si NMR shifted slightly lower field to 112.9 ppm, and the peak at $106.0 \mathrm{ppm}$ is still present, suggesting that the hydrogen treatment causes some changes in the framework 
silinal, but less than the nano-sized ZSM-5 supported NiO sample

In combing the ${ }^{27} \mathrm{Al}$ MAS NMR results of the micro and nano-sized ZSM-5 samples, we can see that the hydrogen treatment that higher temperature of the NiO/ZSM-5 sample has opposite effect on the micro and nano-sized ZSM-5 samples. For the nano-sized ZSM-5 sample, the hydrogen treatment leads to less non-framework AlO4 unit, which may enter the framework, but for micro-sized ZSM-5, the hydrogen treatment leads to more framework $\mathrm{AlO}_{4}$ unit out of the framework. The reasons for these are not clear yet, but there are differences between the structure changes of the nano and micro-sized ZSM-5 supported $\mathrm{NiO}$.

The acidities of the nano-sized and micro-sized ZSM-5 zeolites samples and their supported nickel catalysts were measured using $\mathrm{NH}_{3}-\mathrm{TPD}$, and the results are shown in Fig 6-a and b. It is seen that the nano-sized ZSM-5 zeolite sample has $\mathrm{NH}_{3}$ desorption peaks 100-200 ${ }^{\circ} \mathrm{C}$, which are assigned to the weak and medium acid site over the ZSM-5 catalyst, and caused by the terminal $\mathrm{Si}(\mathrm{OH})$, the peak is broad, suggesting that the acidic sites has a wide distribution range.. A second desorption peak is seen at $360{ }^{\circ} \mathrm{C}$, which is ascribed to the strong acid site, arising from the non-framework $\mathrm{AlO}_{4}$ or the $\mathrm{Q}_{4} 1 \mathrm{Al}$ site. When $1.0 \mathrm{wt} \%$ nickel is loaded over nano-sized ZSM-5 and calcined, maybe due to the NiO replacement of $\mathrm{Al}$, giving rising more verities of $\mathrm{OH}$ groups, as shown in Fig. 3 , the $\mathrm{NH}_{3}$ desorption peak at lower temperature shifts too slightly higher temperature with the weak acid peak centering at $150{ }^{\circ} \mathrm{C}$, and the $\mathrm{NH}_{3}$ desorption peak at higher temperature becomes weaker, maybe due to the less non-framework $\mathrm{AlO}_{4}$ unit after $\mathrm{NiO}$ substitution. However, it is interesting to note that after $\mathrm{H}_{2}$ reduction of the oxide to $400{ }^{\circ} \mathrm{C}$, the $\mathrm{NH}_{3}$ desorption peak at lower temperature further shifted to a higher temperature centering at $185^{\circ} \mathrm{C}$, although the intensity decreased to some extent. However the $\mathrm{NH}_{3}$ desorption peak at higher temperature become more intense and also shifted even to higher temperature. This suggests that the $\mathrm{H}_{2}$ treatment of the $\mathrm{NiO} /$ nano-ZSM-5 changed the catalyst acidity, which may arise from the NiO entering the framework, and generates more $\mathrm{OH}$ groups. 

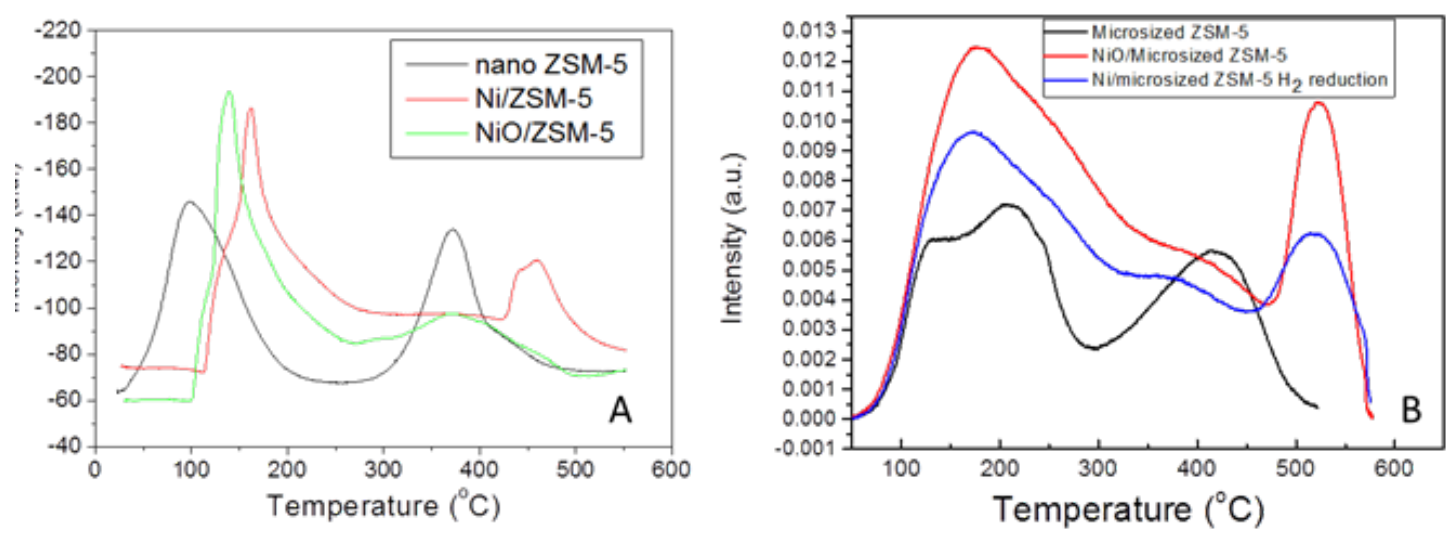

Fig. $6 \mathrm{NH}_{3}$-TPD profiles of the nano and micro-sized ZSM-5 zeolite and their supported $\mathrm{NiO}$ catalysts, a) nano-sized ZSM-5 supported catalyst, b) micro-sized ZSM-5 supported samples

For the micro-sized ZSM-5 zeolite, even with the same Si/Al ratio and same crystalline structure, the crystallite size also has influence on the acidity, as shown in Fig 6-b. The micro-sized ZSM-5 zeolite has a broad distribution both at lower temperature region $\left(100-260{ }^{\circ} \mathrm{C}\right)$ and high temperature region $\left(300-500{ }^{\circ} \mathrm{C}\right)$. This might be due to the broad distribution of Nickel in and outside of the zeolite pore, exerting more effect on the silicanol groups in the catalyst. When $1.0 \mathrm{wt} \% \mathrm{NiO}$ is loaded over the micro-sized ZSM-5, similar to the nano-sized, the $\mathrm{NH}_{3}$ desorption peak intensity at lower temperature increases significantly, suggesting more acidic site generated by loading $\mathrm{NiO}$ over the micro-sized zeolite. In addition, the strong acidic site becomes stronger as the $\mathrm{NH}_{3}$ desorption peak even shifted higher. The treatment of NiO/micro-sized ZSM-5 catalyst with $\mathrm{H}_{2}$ decreases the acidic amount at both higher temperature and lower temperature regions, although the acidic strength of the weaker and strong acid site do not changes significantly.

The above results show that the nano-ZSM-5 and micro-sized ZSM catalyst have different acidic properties, The NiO loading does have significant effect on the ZSM-5 acidic amount and strength, and it increases the acidic amount at lower temperatures and higher temperatures. In the micro-sized ZSM-5, the NiO loading leading to the more acid amount and acid strength, and a broad acid site distribution. In general, it is seen that in both 
micro-sized and nano-sized ZSM-5 zeolite, the loading of nickel increase the strong acidic sites, which is in agreement with the literature results.[23]

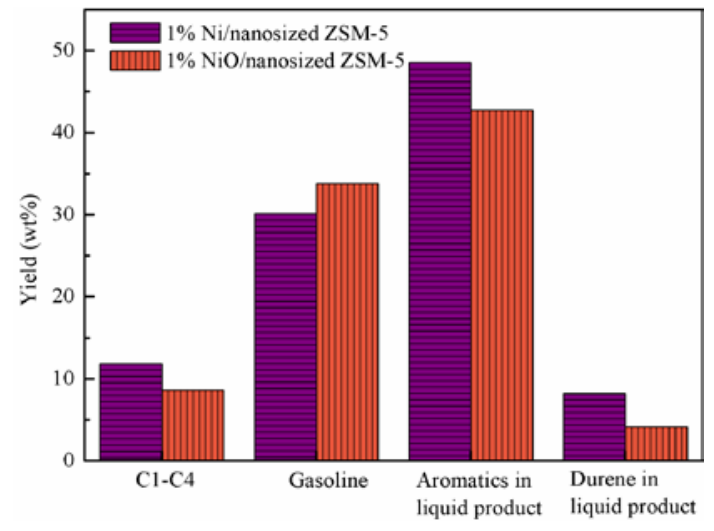

a

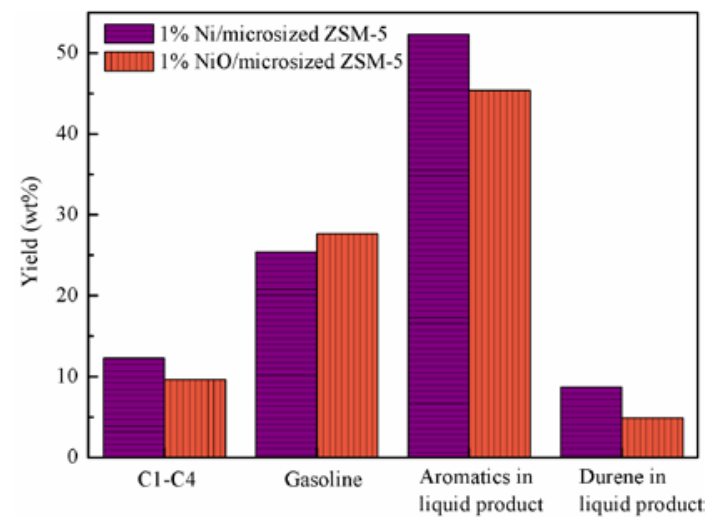

b

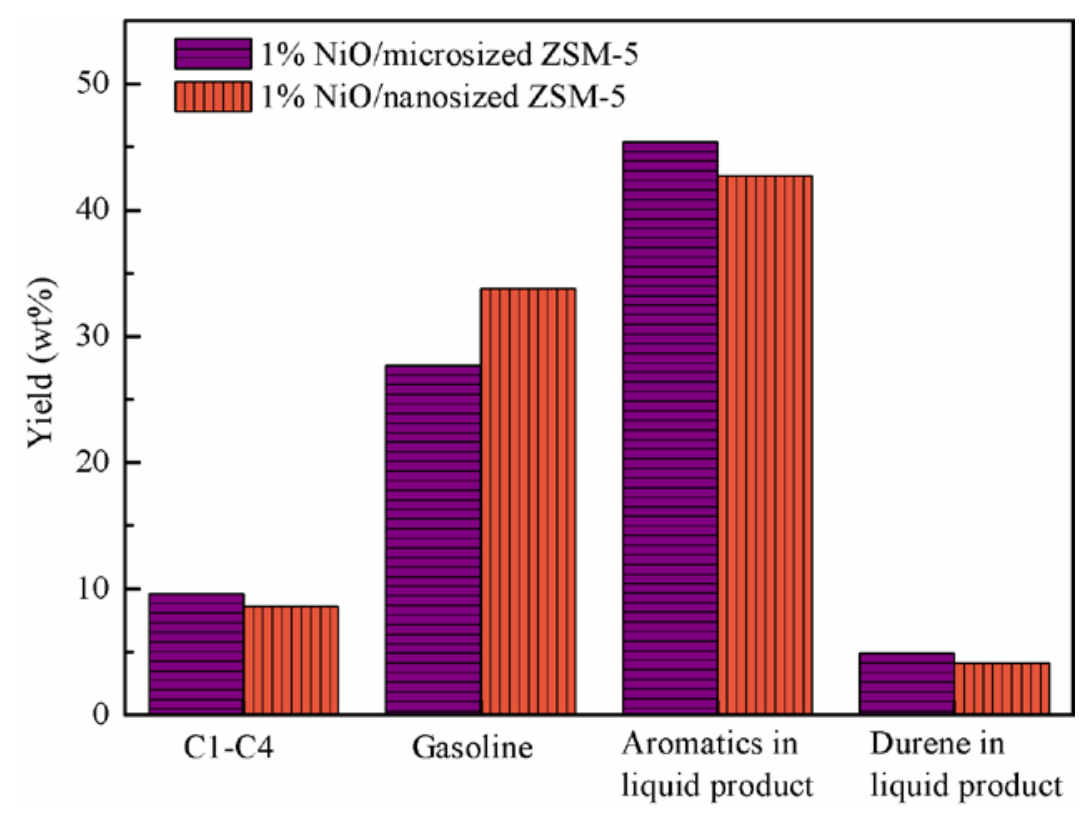

c

Fig.7 Performance comparison of $\mathrm{Ni}$ and NiO supported ZSM-5. (a) nano-sized ZSM-5, (b) micro-sized ZSM-5, and c) 1\% NiO over nano-sized and micro-sized ZSM-5 in MTG reaction

Micro and nano-sized ZSM-5 supported Ni catalysts were tested for methanol to hydrocarbon, which is a very important process for future energy and chemical industry. The results are shown in Fig 7. For NiO/Nano-ZSM-5 sample. The gasoline yield is about 33\%, and aromatics selectivity in the liquid is $42 \%$, less than $10 \%$ of methanol is converted into 
C1-C4 gases hydrocarbons. When the NiO/nano-ZSM-5 is treated with $\mathrm{H}_{2}$ at high temperature, the liquid hydrocarbon yield dropped to about $30.5 \%$, but aromatics do increase in the liquid products, suggesting that the $\mathrm{H}_{2}$ treatment leads to stronger acidity, as the more aromatic is the results of the deep dehydrogenation of the $-\mathrm{CH}_{2}$ groups over the acidic sites.

For the NiO/Micro-sized ZSM-5 sample, the performance for methanol to hydrocarbon process are shown in Fig. 7-b. The C1-C4 product selectivity over the supported $\mathrm{NiO}$ is slightly higher than the nano-ZSM-5, but the gasoline yield is about $28.9 \%$, lower than the nano-zeolite sample, However, the selectivity to aromatics in the liquid product is about $45.2 \%$, which is more than the nano-ZSM-5 supported NiO. The heavy aromatics content, e.g., durene in the liquid products is about $4.8 \mathrm{wt} \%$, which is slightly higher than in the nano-zeolite. After $\mathrm{H}_{2}$ treatment of the NiO/Micro-sized ZSM-5, the gasoline yield decrease to $25 \%$, but the aromatics content does increase significantly compare to the $\mathrm{Ni} /$ nano-sized ZSM-5. The effect of $\mathrm{H}_{2}$ treatment at high temperature may lead to more none-framework $\mathrm{AlO}_{4}$ unit in the micro sized ZSM-5 catalyst, which are mostly Lewis acid sites, leading to deep dehydrogenation content, thus give more aromatics and durene.

In comparing the Fig 7-a and b as shown in Fig 7-c, the higher yield of gasoline over nano-sized ZSM-5 catalyst may result from the smaller crystallite size, which makes the products easy to migrate from the catalyst channels, and thus have less carbon deposition and higher liquid products yield. This has been validated by many researchers [11, 15, 24-27]. 


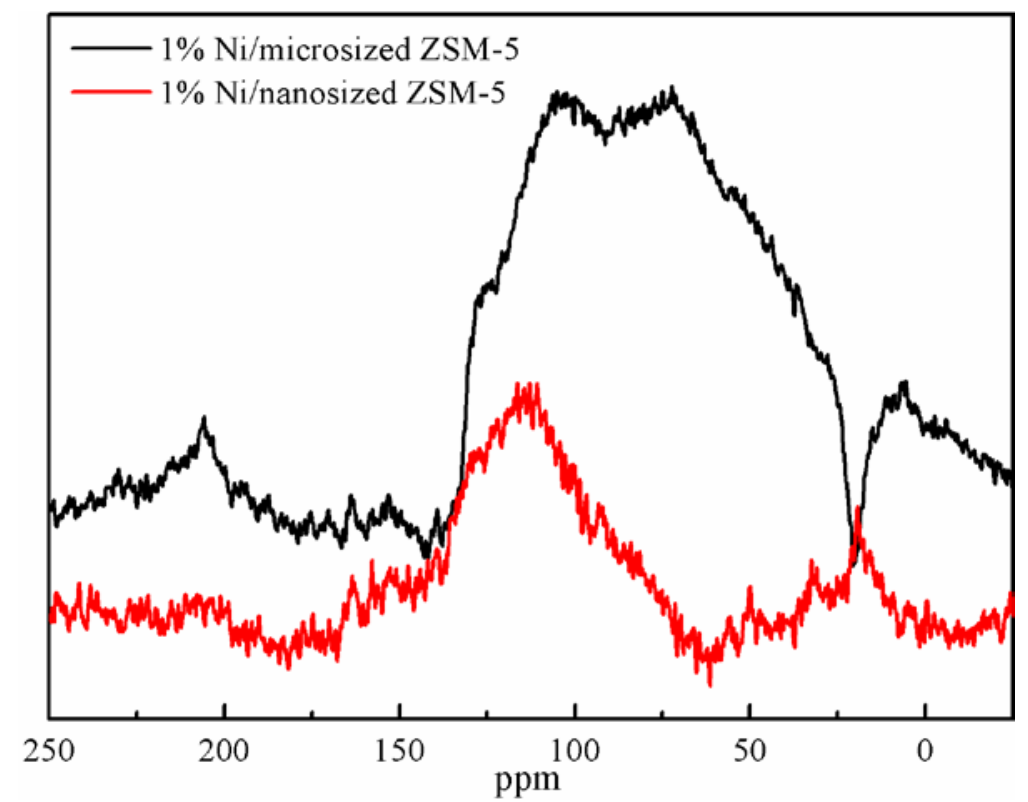

Fig. ${ }^{13} \mathrm{C}$ MAS NMR spectra of coked Ni/microsized and nanosized ZSM-5 after $10 \mathrm{~h}$

The spectra of ${ }^{13} \mathrm{C}$ MAS NMR of the spent micro-sized and nano-sized ZSM-5 supported $\mathrm{Ni}$ catalysts are shown in Fig 8. It is clearly seen that the $1.0 \mathrm{wt} \%$ Ni/Nano-ZSM-5 catalyst has a weak NMR band at about $128 \mathrm{ppm}$, is assigned to aromatic carbons or polyene chains. The peaks below $50 \mathrm{ppm}$, especially these at around $30.0 \mathrm{ppm}$ to $-\mathrm{CH}_{2}$ groups in long paraffinic chain, and $23.0 \mathrm{ppm}\left(\mathrm{CH}_{2}\right.$ groups linked to terminal methyl group). As it indeed there are liquid hydrocarbon products still presenting in the catalyst. For the ${ }^{13} \mathrm{C}$ MAS NMR spectra of the micro-sized ZSM-5 supported Ni catalyst, the carbon peaks is much broader, ranging from $50 \mathrm{ppm}$ to $135 \mathrm{ppm}$ and the peaks intensity is much more stronger, suggesting that there have been much more aromatics and absorbed hydrocarbon in the micro-sized ZSM-5 supported Ni catalysts, this may be explained by the longer channel for the products diffusion, as micro-crystallite ZSM-5 catalyst has longer pore and channel, which makes it difficult for the products with big molecules to diffuse out, thus residing in the catalyst. This results is in agreement tithe catalyst test performance, as the mico-sized ZSM-5, where the micro-sized ZSM-5 catalyst gives less yield of gasoline

The TG-DTA results of the spent nickel catalyst are given in Fig 9, and it is clearly seen that for the nano-sized ZSM-5 supported Ni catalyst more weightloss is seen at temperature below $100{ }^{\circ} \mathrm{C}$, which may be due to the physi-sorption compounds such as moisture or methanol reactant. There is $3.0 \%$ wt. of weight loss at temperature $400-800{ }^{\circ} \mathrm{C}$, which is 
assigned to the burning of the heavy coking species like aromatics in the catalyst pore. However, for the micro-sized ZSM-5 supported Ni catalyst, there is much less weighloss seen at temperature below $100{ }^{\circ} \mathrm{C}$, which show that the physi-sorbed components such as methanol or moisture is much less, but a much big weight loss is seen from $400-800{ }^{\circ} \mathrm{C}$, which is due to the hard coking species, this also confirm the ${ }^{13} \mathrm{C}$ NMR results, There have been much more hard-coking species in the micro-sized ZSM-5 supported Ni catalyst, this is due to the increase of acidity in the $\mathrm{Ni}$ loaded catalyst, but mostly due to the bigger size of the micro-sized ZSM-5, leading them to a slow diffusion of the organic compounds products,
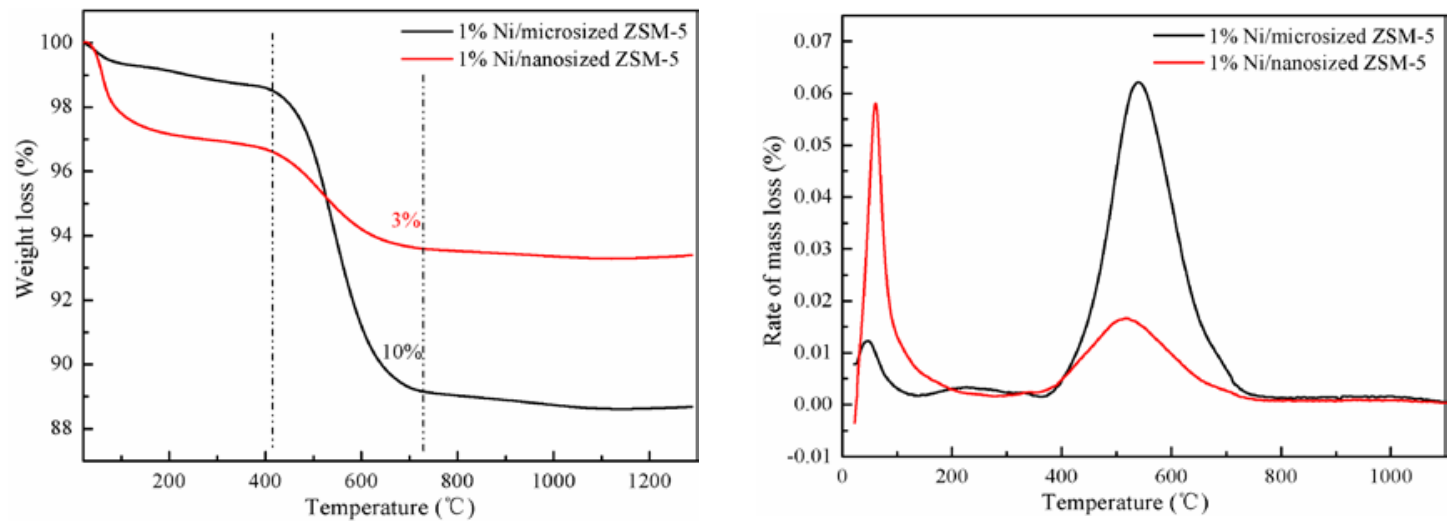

Fig.9 TG and DTA profiles of used Ni/microsized and nanosized ZSM-5 after 10 hs time on stream.

\section{Conclusion:}

Nano- and micro-sized ZSM-5 zeolite supported nickel oxide catalysts have been prepared and tested for methanol to hydrocarbon process. The loading of low amount of nickel has significant effect on the acidity and coordination environment of silicon and aluminum, and also the acidic sites. There are clear differences between the nano and micro-sized ZSM-5 supported Ni catalyst.

The hydrogen treatment of the nano-ZSM-5 supported NiO leads to some non-framework $\mathrm{AlO}_{4}$ re-locate in the framework, while has little effect on the micro-sized ZSM-5 supported NiO, which has higher stability.

The nano-sized ZSM-5 supported NiO gives more liquid yield of hydrocarbon than 
micro-sized ZSM-5 supported NiO. The high temperature hydrogen treatment leads to the lower yield of liquid hydrocarbon but higher selectivity to aromatics, although the micro-sized ZSM-5 always has lower yields of HCs and higher selectivity to aromatics, which shows that the crystallite size does have a dominant effect on the reaction, as micro-crystallite size has a longer channel for the products to diffuse than the nano-zeolite. As reflected in the test results. The micro-sized ZSM-5 supported NiO catalyst has much higher content of coking species, which has a very broad range of carbon species, while nano-sized ZSM-5 catalysts have less coking accumulated in the catalyst, which is mainly aromatics.

Compared to the ZSM-5 only catalyst for methanol to hydrocarbon, the loading of $1.0 \mathrm{wt} \% \mathrm{NiO}$ with or without $\mathrm{H}_{2}$ treatment is not beneficial to the liquid product yield, but help to increase the aromatic selectivity. Therefore the low content nickel containing catalyst may be more suitable for methanol to aromatics process.

\section{Acknowledgment}

We would like to thank Shanxi University Future Development Foundation for their support, and Dr Fei Liu would like to thank Chinese Scholarship Council for the supporting academic visitor research in Oxford University.

\section{References}

1. Goeppert, A., et al., Recycling of carbon dioxide to methanol and derived products - closing the loop. Chem. Soc. Rev., 2014. 43(23): p. 7995-8048.

2. Olah, G.A., G.K.S. Prakash, and A. Goeppert, Anthropogenic Chemical Carbon Cycle for a Sustainable Future. J. Am. Chem. Soc., 2011. 133(33): p. 12881-12898.

3. Olah, G.A., Beyond oil and gas: The methanol economy. Angew. Chem., Int. Ed., 2005. 44(18): p. 2636-2639.

4. Wu, M.M. and W.W. Kaeding, Conversion of methanol to hydrocarbons. II. Reaction paths for olefin formation over HZSM-5 zeolite catalyst. J. Catal., 1984. 88(2): p. 478-89.

5. Haag, W.O., R.M. Lago, and P.G. Rodewald, Aromatics, light olefins and gasoline from methanol: mechanistic pathways with ZSM-5 zeolite catalyst. J. Mol. Catal., 1982. 17(2-3): p. 161-9.

6. Conte, M., et al., Modified zeolite ZSM-5 for the methanol to aromatics reaction. Catal. Sci. Technol., 2012. 2(1): p. 105-112.

7. Firoozi, M., M. Baghalha, and M. Asadi, The effect of micro and nano particle sizes of H-ZSM-5 on the selectivity of MTP reaction. Catal. Commun., 2009. 10(12): p. 1582-1585. 
8. Wang, K. and X. Wang, Comparison of catalytic performances on nanoscale HZSM-5 and microscale HZSM-5. Microporous Mesoporous Mater., 2008. 112(1-3): p. 187-192.

9. Rownaghi, A.A., et al., Selective dehydration of methanol to dimethyl ether on ZSM-5 nanocrystals. Appl. Catal., B, 2012. 119-120: p. 56-61.

10. Jang, H.-G., et al., SAPO-34 and ZSM-5 nanocrystals' size effects on their catalysis of methanol-to-olefin reactions. Appl. Catal., A, 2012. 437-438: p. 120-130.

11. Aramburo, L.R., et al., Interplay between nanoscale reactivity and bulk performance of H-ZSM-5 catalysts during the methanol-to-hydrocarbons reaction. J. Catal., 2013. 307: p. 185-193.

12. Jung, J., et al., Zeolite nanosheet of a single-pore thickness generated by $a$ zeolite-structure-directing surfactant. J. Mater. Chem., 2012. 22(11): p. 4637-4640.

13. Hu, S., et al., Selective formation of propylene from methanol over high-silica nanosheets of MFI zeolite. Appl. Catal., A, 2012. 445-446: p. 215-220.

14. Ni, Y., et al., The preparation of nano-sized H[Zn, Al]ZSM-5 zeolite and its application in the aromatization of methanol. Microporous Mesoporous Mater., 2011. 143(2-3): p. 435-442.

15. Mann, J., et al., Metal oxide-zeolite composites in transformation of methanol to hydrocarbons: do iron oxide and nickel oxide matter? RSC Adv., 2016. 6(79): p. 75166-75177.

16. Van der Borght, K., V.V. Galvita, and G.B. Marin, Ethanol to higher hydrocarbons over Ni, Ga, Fe-modified ZSM-5: Effect of metal content. Appl. Catal., A, 2015. 492: p. 117-126.

17. Niu, X., et al., Influence of preparation method on the performance of Zn-containing HZSM-5 catalysts in methanol-to-aromatics. Microporous Mesoporous Mater., 2014. 197: p. 252-261.

18. Beznis, N.V., B.M. Weckhuysen, and J.H. Bitter, CU-ZSM-5 Zeolites for the Formation of Methanol from Methane and Oxygen: Probing the Active Sites and Spectator Species. Catal. Lett., 2010. 138(1-2): p. 14-22.

19. Han, S., et al., Direct partial oxidation of methane over ZSM-5 catalyst: metals effects on higher hydrocarbon formation. J. Catal., 1994. 148(1): p. 134-7.

20. Dyballa, M., et al., Bronsted sites and structural stabilization effect of acidic low-silica zeolite A prepared by partial ammonium exchange. Microporous Mesoporous Mater., 2015. 212: p. 110-116.

21. Schmitt, K.D., J. Haase, and E. Oldfield, Spectral editing: a quantitative application of spin-echo nuclear magnetic resonance spectroscopy to the study of $27 \mathrm{Al}$ in zeolite catalysts. Zeolites, 1994. 14(2): p. 89-100.

22. Hiradate, S., Speciation of aluminum in soil environments application of NMR technique. Soil Sci. Plant Nutr. (Tokyo, Jpn.), 2004. 50(3): p. 303-314.

23. Zhang, B., et al., Synthesis of Ni/mesoporous ZSM-5 for direct catalytic conversion of cellulose to hexitols: modulating the pore structure and acidic sites via a nanocrystalline cellulose template. Green Chem., 2016. 18(11): p. 3315-3323.

24. Wan, Z., et al., Effect of SiO2/AI2O3 ratio on the performance of nanocrystal ZSM-5 zeolite catalysts in methanol to gasoline conversion. Appl. Catal., A, 2016. 523: p. 312-320.

25. Gao, Y., et al., Modified seeding method for preparing hierarchical nanocrystalline ZSM-5 catalysts for methanol aromatisation. Microporous Mesoporous Mater., 2016. 226: p. 251-259.

26. Li, J., et al., Hydrothermal synthesis of nanocrystalline H[Fe, Al]ZSM-5 zeolites for conversion of methanol to gasoline. Energy Convers. Manage., 2015. 93: p. 259-266. 
27. Shen, K., et al., Atmospheric pressure synthesis of nanosized ZSM-5 with enhanced catalytic performance for methanol to aromatics reaction. Catal. Sci. Technol., 2014. 4(11): p. 3840-3844. 